\title{
Quality Matters: A Meta-Analysis on Components of Healthy Family Meals
}

\author{
Mattea Dallacker and Ralph Hertwig \\ Max Planck Institute for Human Development, Berlin, Germany
}

\author{
Jutta Mata \\ University of Mannheim and Max Planck Institute for Human \\ Development, Berlin, Germany
}

\begin{abstract}
Objective: A greater frequency of family meals is associated with better diet quality and lower body mass index (BMI) in children. However, the effect sizes are small, and it remains unclear which qualitative components of family meals contribute to these positive health outcomes. This meta-analysis synthesizes studies on social, environmental, and behavioral attributes of family meals and identifies components of family meals that are related to better nutritional health in children. Method: A systematic literature search (50 studies; 49,137 participants; 61 reported effect sizes) identified 6 different components of healthy family mealtimes. Separate meta-analyses examined the association between each component and children's nutritional health. Age (children vs. adolescents), outcome type (BMI vs. diet quality), and socioeconomic status (SES; controlled vs. not controlled for SES) were examined as potential moderators. Results: Positive associations consistently emerged between 5 components and children's nutritional health: turning the TV off during meals $(r=.09)$, parental modeling of healthy eating $(r=.12)$, higher food quality $(r=.12)$, positive atmosphere $(r=.13)$, children's involvement in meal preparation $(r=.08)$, and longer meal duration $(r=.20)$. No moderating effects were found. Conclusions: How a family eats together shows significant associations with nutritional health in children. Randomized control trials are needed to further verify these findings. The generalizability of the identified mealtime components to other contexts of social eating is also discussed.
\end{abstract}

Keywords: child, body mass index, diet, family meals, meta-analysis

Supplemental materials: http://dx.doi.org/10.1037/hea0000801.supp

The increasing prevalence of overweight and obesity worldwide, especially in children, is the public health challenge of modern times. In the United States, for example, more than $18 \%$ of children and adolescents are obese (Hales, Carroll, Fryar, \& Ogden, 2017). One of the major drivers of obesity is an unbalanced diet (Rosenheck, 2008). Children in particular eat more sugar and fewer fruits and vegetables than recommended (Hebestreit et al., 2017). Because two thirds of children's daily calories stem from food prepared at home (Poti \& Popkin, 2011), family meals offer a promising entry point for change.

This article was published Online First September 26, 2019.

Mattea Dallacker and Ralph Hertwig, Center for Adaptive Rationality, Max Planck Institute for Human Development, Berlin, Germany; Jutta Mata, Health Psychology, Department of Social Sciences, University of Mannheim, and Center for Adaptive Rationality, Max Planck Institute for Human Development.

We are grateful to Susannah Goss and Deb Ain for editorial assistance. We also thank the library of the Max Planck Institute for Human Development, particularly Nicole Engelhardt, for help with the literature search; Eveline Soeder and Anna Dania Esch for their support in preparing the analyses; and Claus Vögele for comments on an earlier version of this article. The authors declare no conflict of interest.

Correspondence concerning this article should be addressed to Mattea Dallacker, Center for Adaptive Rationality, Max Planck Institute for $\mathrm{Hu}-$ man Development, Lentzeallee 94, 14195 Berlin, Germany. E-mail: dallacker@mpib-berlin.mpg.de
Parents govern the variety (or lack thereof) in their children's food; they guide and, through their own eating behavior, model food intake (Savage, Fisher, \& Birch, 2007). In so doing, they shape the development of their children's eating habits and food preferences. Despite demographic and lifestyle changes, U.S. families still have on average 5.1 family meals per week (Saad, 2013), and each shared meal presents a potential learning opportunity (Fiese \& Schwartz, 2008). It is therefore important to understand the role that family meals and their behavioral correlates can play in preventing childhood overweight and obesity (for reasons of simplicity, in what follows, all minors are generally referred to as "children," unless an explicit contrast is being drawn between children and adolescents).

Dallacker, Hertwig, and Mata (2018) recently conducted a metaanalysis on the relationship between the quantity of family meals and children's nutritional health. They analyzed 57 studies and found that a greater frequency of family meals was significantly associated with lower body mass index (BMI; $r=-.05$ ), more healthy eating $(r=.10)$, and less unhealthy eating $(r=-.04)$ in children. These results suggest two conclusions: First, the frequency of family meals is positively related to children's better diet quality and healthier BMI. Second, the potential impact of the quantity of family meals per se on children's nutritional health appears to be quite small. The meta-analysis by Dallacker et al. focused on the frequency of family meals. However, what makes family meals healthy-that is, what happens during these meals that promotes children's health-is an open question. 
Family systems theory (Cox \& Paley, 1997) suggests that family functioning, including family cohesion as well as supportive and warm family interactions, are key factors in promoting health behavior in children (Kitzman-Ulrich et al., 2010). Meaningful rituals such as family meals may therefore play an important role in family functioning, because they have the potential to provide structure and a supportive emotional climate (Spagnola \& Fiese, 2007). Thus, spending time with family members provides an opportunity for both positive and negative interactions. Thus, the quality of how families eat together might play an even more important role than does the mere quantity of family meals. In their review, Kitzman-Ulrich et al. (2010) found that a positive family system can promote healthy eating through role modeling and providing social support, healthy foods, and a positive climate for health behavior change. Furthermore, a number of recent studies have investigated how various components of family meals relate to children's nutritional health; for instance, when families enjoy eating together, children are less likely to be overweight (e.g., Berge et al., 2014). Yet findings on the effects of specific family meal components are mixed. Some studies have found that children's nutritional health is better when the TV is turned off during family meals (e.g., Roos et al., 2014); others have found no such effect (e.g., van Zutphen, Bell, Kremer, \& Swinburn, 2007). Or consider the prominent hypothesis that longer meal duration increases the amount of food eaten (de Castro, 1994). Contrary to this hypothesis, children who spend less time at the dinner table are more likely to be overweight (Jacobs \& Fiese, 2007).

Further complicating matters, reviews of the effects of various family meal components have lacked quantitative stringency. Specifically, narrative reviews of the literature (e.g., Fulkerson, Larson, Horning, \& Neumark-Sztainer, 2014; Martin-Biggers et al., 2014) have suggested that different mealtime components may be beneficial for children's nutritional health, but the reviews were not systematic, nor did they quantify effect sizes or focus explicitly on family meals (e.g., Pearson, Biddle, \& Gorely, 2009). The current meta-analysis is therefore an important next step toward understanding how and how strongly the quality of a family meal-that is, its specific components—relates to children's nutritional health.

The goal of this meta-analysis was to identify components of family meals that are potentially beneficial for children's nutritional health. These components were defined as social, environmental, and behavioral attributes of family meals, including food quality, that have the potential to influence two outcomes: to facilitate a healthy body weight and to boost children's diet quality. The strength of the relationship between a mealtime component and children's nutritional health may depend on the type of outcome. For instance, body mass index (BMI) is influenced not only by eating and related factors but also by physical activity (Hruby et al., 2016); stronger effects were therefore expected for diet quality than for BMI. Characteristics of the study population such as age and socioeconomic status may also influence the effect of a mealtime component. Adolescents' eating behavior is more strongly influenced by peers, school, media, or cultural norms than is that of younger children (Story, Neumark-Sztainer, \& French, 2002). Thus, the influence of family meals may decrease as children get older. Lower socioeconomic status (SES) has been linked to poorer diet and a higher risk of overweight (Appelhans et al., 2012; Morgenstern, Sargent, \& Hanewinkel, 2009). Families with a lower socioeconomic status also report more family chaos and less frequent family meals. Consequently, the potential positive effect of a mealtime component may be lower in families with a lower SES.

Three research questions were addressed: (a) What are frequently investigated family mealtime components in observational studies that assessed the relationship between one (or more) components and nutritional health in children? (b) How strong is the relationship between the identified mealtime components and children's nutritional health? and (c) Do age of the target population (children vs. adolescents), outcome type (BMI vs. diet quality), and SES (controlled vs. not controlled for SES) moderate the association between different mealtime components and children's nutritional health?

\section{Method}

This meta-analysis complies with the Preferred Reporting Items for Systematic Reviews and Meta-Analyses (PRISMA; Moher, Liberati, Tetzlaff, Altman, \& The PRISMA Group, 2009). The PRISMA checklist is available in the online supplemental materials.

\section{Search Strategy}

The search strategy was developed by the authors and reviewed by an independent research librarian who specialized in systematic literature search in the social sciences. This resulted in a three-step search strategy. First, a systematic literature search was conducted using search terms in the following databases:

Web of Science: ("family meal" OR "mealtime*" OR "shared meal" OR "dinner") AND ("BMI" OR "body mass index" OR "overweight" OR "obesity" OR "food intake" OR "eat" "diet" OR "nutrition" [Refined by topic "child", OR "adolescent", OR “young adults"]),

PubMed (Medical Subject Headings [MeSH]): (("Diet" OR "feeding behavior") AND "family" [Filter: "preschool child," "child," "adolescent"]), and

PsycINFO: ("body mass index" OR "body weight" OR "obesity" OR "overweight" OR "diets" OR "eating behavior" OR "food" OR "food preferences" OR "nutrition") AND ("mealtimes" [Thesaurus] OR “meal"”, OR “dinner" OR "lunch").

The exact search terms differed between databases depending on whether free or controlled vocabulary was used (i.e., MeSH terms in Pubmed; Thesaurus in PsycINFO). There was no restriction on the year of publication. Unpublished studies (e.g., dissertations, conference abstracts) written in English or German were also included in the analysis. Second, forward searches were performed on relevant studies found in the literature search, with Web of Science being used to identify later articles that cited them. Third, backward searches were performed on literature reviews; that is, their reference lists were reviewed. Throughout, the key terms used were selected to cast a wide net and identify studies that did not necessarily include mealtime components in their title or abstract. This procedure is likely to have increased the probability of including studies with nonsignificant results. 


\section{Screening for Eligibility}

Studies had to meet three criteria to be included. They had to (a) examine at least one component of the family mealtime, (b) include one indicator of nutritional health that was child- or adolescent-focused, and (c) report one bivariate statistical association between the relevant component and indicators of nutritional health. Studies were excluded if they focused on a specific population that had feeding problems or required a special diet (e.g., children with diabetes). Manifestly irrelevant studies (e.g., focusing on animals, older adults, or eating disorders) were excluded. For all other studies, the full text was screened to determine eligibility. Figure 1 shows a PRISMA flow diagram (cf. Moher et al., 2009) of the screening process. To establish interrater reliability, the first author and a trained research assistant screened approximately $30 \%$ of the articles against the criteria just discussed. Because the agreement rate (Cooper, Hedges, \& Valentine, 2009) was very high (90\%-95\%), the remaining $70 \%$ of articles were processed independently by one rater. Any screening issues were discussed and resolved with the second and third authors.

\section{Categorization of Components}

There is no objective criterion defining the number of studies needed to conduct a meta-analysis. We used the threshold of five or more studies for random-effects meta-analyses as suggested by Jackson and Turner (2017). Mealtime practices that represent a summary score of more than one component (e.g., "negative mealtime practices," composed of watching TV, eating fast food, and leaving the table during meals; McCurdy, Gorman, Kisler, \& Metallinos-Katsaras, 2014) were not included in this metaanalysis, because they do not allow for estimating the effect of a specific mealtime component.

\section{Coding of Studies}

Studies were coded on the following dimensions according to established guidelines (Card, 2011):

- Sample characteristics: demographic features (ethnic composition, age), sample size;

- Measurement characteristics: source of information (child, parent report, observer) and type and description of measure used (nutritional health and component);

- Design characteristics: cross-sectional versus longitudinal;

- Source characteristics: author, year of study, publication type; and

- Study quality: study design, convenience sampling, specific subpopulation, reliability and validity of relevant measures, response rate (participation rate at least 50\%), and pilot testing of survey instruments.

An adapted version of the data extraction form developed and tested within a meta-analysis on family meal frequency (Dallacker et al., 2018) was used. Data were extracted by the first author, and each data point was independently checked by a trained research assistant. Disagreements were resolved by discussion with the second and third authors.

\section{Outcome: Nutritional Health}

This meta-analysis focuses on two outcomes that are frequently investigated by studies on family meals: BMI and diet quality. BMI is an indirect measure of body fat and obesity, both of which are linked to serious health conditions such as diabetes. It is influenced by not only what but also how a person eats (e.g., speed of eating, food quantity; J. O. Hill, Wyatt, \& Peters, 2012; Nagahama et al., 2014), thereby providing information that is complementary to diet quality, the average consumption of foods that are related to obesity. It is important to note that BMI does not distinguish between fat and muscle mass (Rothman, 2008). Further, BMI is just one of several risk factors for chronic degenerative diseases, and its effects can be offset by lifestyle factors (e.g., Bombak, 2014). Therefore, the current metaanalysis also included studies that assessed diet quality. This includes healthy/nutrient-dense foods (e.g., fruits, vegetables), unhealthy/ energy-dense foods (e.g., soda, sweet and salty snacks), and summary scores of healthy and/or unhealthy foods (e.g., the Healthy Eating Index). Like BMI, diet quality is an important predictor of health. Better diet quality can protect against heart disease and other chronic diseases (Aune et al., 2017). BMI and diet quality are both health-related variables that can be influenced through nutrition-related behavior during family meals. Consequently, effect sizes are reported both separately for BMI and diet quality and combined into one factor: nutritional health.

\section{Effect Size}

The correlation coefficient $r$ was chosen as an effect size of the associations between component of family mealtime and nutritional health for several reasons: Many of the studies reported $r$ values; they can be computed from a wide range of statistics, most measures were continuous (or artificially dichotomized), and $r$ is easily interpretable. The results were coded such that a positive $r$ indicates that a component is positively associated with better nutritional health. To be consistent for all variables, the direction of the $r$ value was reversed for BMI and unhealthy/energy dense foods or if negative mealtime components were analyzed (e.g., watching TV instead of TV off). If available, unadjusted $r$ values were used. If $r$ values were not available but standardized beta values were, those were used (Becker \& Wu, 2007; Peterson \& Brown, 2005). Other statistics, such as $t$ test or odds ratios, were converted into $r$ values (Borenstein, Hedges, Higgins, \& Rothstein, 2009; Card, 2011). If a study did not report sufficient statistics to calculate an $r$ value, the authors were contacted up to two times. Seven of the 15 authors contacted responded.

\section{Artifact Corrections}

Dichotomizing a continuous variable attenuates its association with other variables (Card, 2011). Because some of the primary studies included may be affected by this artifact, $r$ was corrected whenever continuous variables were dichotomized (e.g., when BMI was measured but the analysis was based on the BMI categories "normal" vs. "overweight"; for details, see Hunter \& Schmidt, 2004, p. 36).

\section{Data Synthesis: Estimating Overall Effect Sizes for Mealtime Components}

A separate meta-analysis was conducted for each component identified. Furthermore, $r$ values were transformed using variancestabilizing Fisher's $z$ transformation (Borenstein et al., 2009), and 


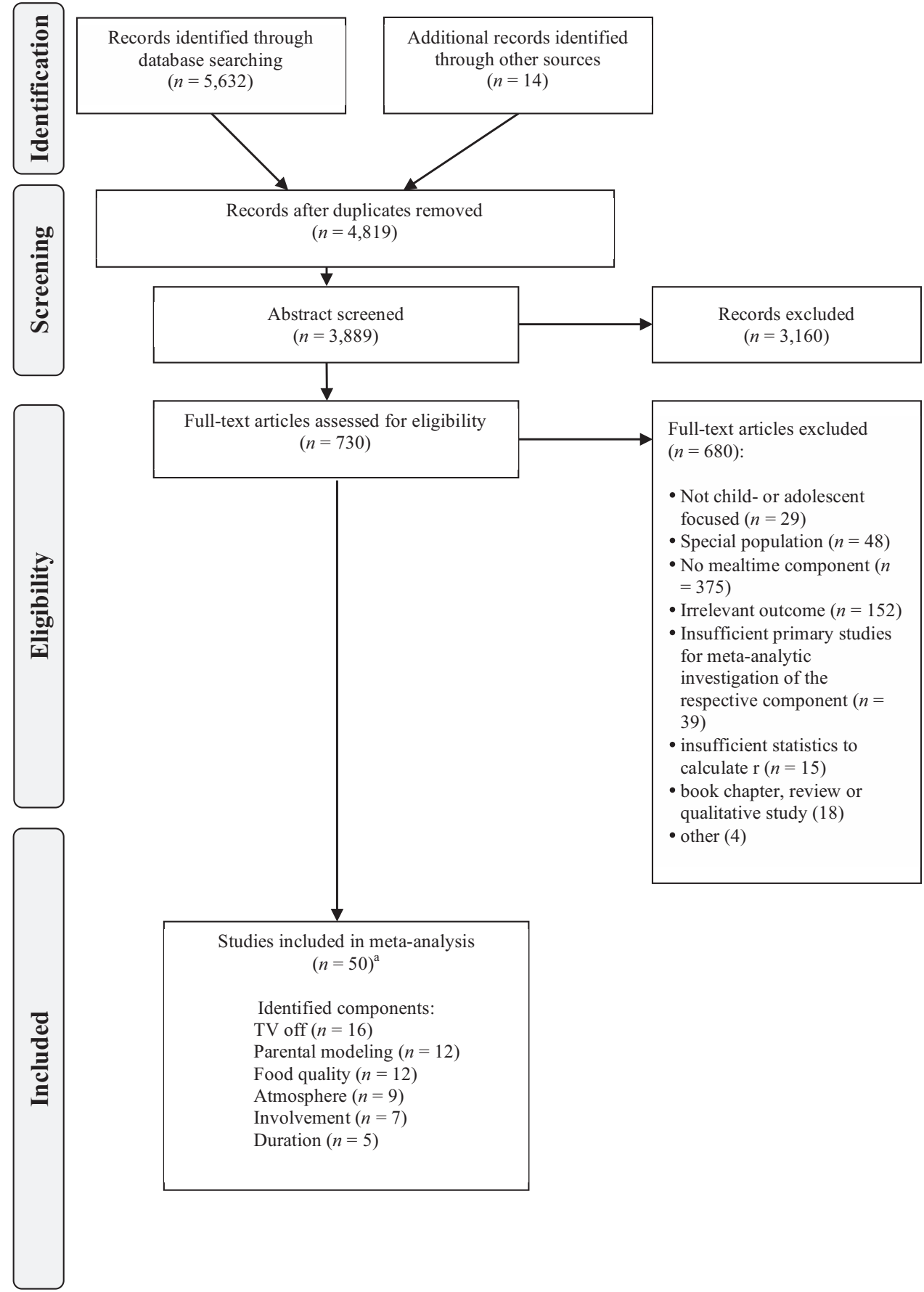

Figure 1. PRISMA flow diagram documenting how articles were identified for the meta-analysis. $n$ indicates

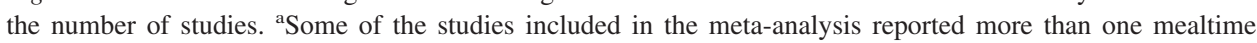
component: $n=41$ examined one component, $n=5$ examined two, and $n=3$ examined three; accordingly the number of studies included $(n=50)$ is not equal to the sum of the studies addressing each mealtime component.

all analyses used the $r$ - to $z$-transformed values. For forest plots and tables, pooled effect sizes were back-transformed to $r$ values.

A random-effects-size approach was used to calculate a pooled effect size with $95 \%$ confidence intervals (CIs). Random-effects models do not assume a single effect size but a distribution of population effect sizes; consequently, they consider systematic variance between studies (Borenstein et al., 2009). Random-effects models were used because the primary studies differed in how they examined specific components and nutritional health (see the Results section). For each component, a pooled effect size was calculated for BMI, for diet quality, and for nutritional health (i.e., for BMI and diet quality combined). 


\section{Heterogeneity}

$Q$ tests were calculated to assess the null hypothesis of homogeneity among effect sizes within one mealtime component. A nonsignificant $Q$ test indicates that between-studies variance stems from random rather than systematic differences. Heterogeneity was quantified with $I^{2}$ statistics indicating the degree of systematic variance between studies (Huedo-Medina, Sánchez-Meca, MarínMartínez, \& Botella, 2006): An $I^{2}$ value of 0 means that betweenstudies variance results from random error; values above 0 indicate the proportion of systematic between-studies variance.

\section{Moderator Analyses}

Moderator analyses were conducted to identify conditions under which components have particularly strong effects and to shed light on sources of heterogeneity. Outcome type (BMI vs. diet quality), age of the target population (children vs. adolescents), and SES (controlled vs. not controlled for SES) were examined as potential moderators. Moderator analyses were conducted for only components investigated in more than 10 studies (Borenstein et al., 2009).

\section{Study Quality}

Methodological quality was assessed using the following criteria adapted from Card (2011) and Agarwald, Guyatt, and Busse (2019): study design (cross-sectional or longitudinal), convenience sampling, specific subpopulation, reliability and validity of relevant measures, response rate (participation rate at least 50\%), and pilot testing of survey instruments. See Table S3 in the online supplemental materials for more details. Primary studies were coded by two independent raters. The moderating effect of the quality sum score was examined for mealtime components featured in 10 or more studies.

\section{Publication Bias}

Funnel plots were used to investigate the possibility that studies finding nonsignificant results were less likely to be published. Funnel plots are scatterplots of effect sizes in primary studies and their standard errors; asymmetric funnel plots may indicate publication bias (Light, Singer, \& Willet, 1994). Egger's linear regression method was used to test for funnel plot asymmetry. Additionally, the "trim and fill" method was applied to impute suspected missing studies until the studies were symmetrically distributed around the pooled effect size; an adjusted effect size was then computed (Duval \& Tweedie, 2000).

\section{Multiple Effect Sizes From Single Studies}

Some of the studies reported data from two or more independent subgroups (e.g., girls and boys; low and high SES). In these cases, each subgroup was treated as a separate study, with a pooled effect size being computed for each. Some of the studies reported multiple results for the same sample (e.g., BMI and diet quality). Others shared the same sample but reported on different outcomes. In these cases, a pooled effect size was computed, taking the correlation among the outcomes into account (Borenstein et al., 2009). In cases where both outcome types (BMI and diet quality) were investigated as moderators, separate effect sizes were calcu- lated. All analyses were implemented using the metafor package in $R$ (Version 3.1.1; Viechtbauer, 2010).

\section{Results}

The keyword search yielded 4,819 potentially relevant articles. After screening, 50 studies were included in the meta-analysis (see Figure 1). Table S1 in the online supplemental materials lists the excluded studies and the reasons for their exclusion. The 50 articles included in the meta-analysis are listed in the online supplemental materials.

\section{Components Identified}

Six mealtime components were examined in at least five studies and were thus included in the analysis; 61 relevant effect sizes were reported. Specifically, studies examining TV off $(k=16)$ asked participants how often they watched TV during shared meals. Studies assessing parental modeling $(k=12)$ asked whether parents' eating behavior provided a model for the quantity or quality of food consumed-either directly, by asking whether parents modeled healthy food intake at mealtimes (e.g., eating vegetables), or indirectly, by asking whether they ate the same food as did their children during family meals. Studies examining food quality $(k=12)$ asked how often the family ate vegetables, home-cooked meals, fast food takeouts, or at fast food restaurants. Studies examining atmosphere $(k=9)$ assessed the mood during shared meals - some using parental self-reports, others using expert ratings of videotaped family meals. Studies assessing children's involvement in meal preparation $(k=7)$ asked how involved a child was in preparing meals. Finally, studies investigating duration of meals $(k=5)$ assessed how long family meals lasted by measuring the average length of videotaped family meals or by asking whether mealtimes were rushed.

Feeding styles (i.e., parental strategies influencing the amount and type of food consumed by their children) are another important component identified in the literature. However, the studies differed substantially in how they defined and measured feeding styles. Given that most feeding styles include aspects outside the family meal (e.g., snacking behavior), they were not included in this meta-analysis.

\section{Study Characteristics}

Beyond mealtime components, the two other key concepts in the literature analysis were family meals and nutritional health. Some studies assessed main meals in general; others assessed dinner, lunch, or breakfast separately. Nutritional health was analyzed in terms of children's BMI or diet quality. BMI was assessed as either a continuous or a categorical (normal weight, overweight, obesity) measure. Diet quality was measured by food-frequency questionnaires assessing the intake of healthy and unhealthy foods either on a continuous scale (e.g., amount of fruits, vegetables, and fast food consumed per day) or as a categorical measure (e.g., whether a child eats five or more portions of fruits and vegetables per day).

In total, 50 studies with a total of 49,137 participants (range = 40-4,072) were analyzed. Of these, 41 studies examined one component, five studies examined two, and three studies examined three. Table 1 summarizes the characteristics of the studies included (for more details, see Table S2 in the online supplemental materials). 
Table 1

Characteristics of the Studies Included in the Meta-Analysis by Mealtime Component

\begin{tabular}{|c|c|c|c|c|c|c|}
\hline Variable and category & $\mathrm{TV}(k=16)$ & $\mathrm{MO}(k=12)$ & $\mathrm{QU}(k=12)$ & $\operatorname{AT}(k=9)$ & $\mathrm{IN}(k=7)$ & $\mathrm{DU}(k=5)$ \\
\hline \multicolumn{7}{|l|}{ Location } \\
\hline United States, Canada & 9 & 7 & 10 & 5 & 3 & 4 \\
\hline Europe $^{\mathrm{a}}$ & 2 & 4 & 0 & 2 & 2 & 1 \\
\hline Australia & 2 & 1 & 2 & 2 & 2 & 0 \\
\hline Middle and South America ${ }^{b}$ & 2 & 0 & 0 & 0 & 0 & 0 \\
\hline China & 1 & 0 & 0 & 0 & 0 & 0 \\
\hline \multicolumn{7}{|l|}{ Period of study } \\
\hline 2000-2009 & 3 & 1 & 4 & 1 & 2 & 1 \\
\hline 2010-2019 & 13 & 11 & 8 & 9 & 4 & 4 \\
\hline \multicolumn{7}{|l|}{ Study design } \\
\hline Cross-sectional & 16 & 12 & 10 & 9 & 7 & 4 \\
\hline Longitudinal & 0 & 0 & 1 & 0 & 0 & 1 \\
\hline Cross-sectional and longitudinal & 0 & 0 & 1 & 0 & 0 & 0 \\
\hline \multicolumn{7}{|l|}{ Child age } \\
\hline Children (2-10 years) & 10 & 9 & 5 & 6 & 3 & 5 \\
\hline Adolescents (11-18 years) & 6 & 3 & 7 & 3 & 4 & 0 \\
\hline \multicolumn{7}{|l|}{ Nutritional health outcome assessed } \\
\hline BMI & 5 & 1 & 7 & 5 & 0 & 4 \\
\hline Diet quality & 10 & 8 & 4 & 3 & 6 & 1 \\
\hline BMI and diet quality & 1 & 3 & 1 & 1 & 1 & 0 \\
\hline \multicolumn{7}{|l|}{ Definition of family meal } \\
\hline Meal (unspecified) & 9 & 9 & 7 & 4 & 4 & 1 \\
\hline Dinner & 7 & 3 & 5 & 4 & 3 & 4 \\
\hline Lunch & 0 & 0 & 0 & 1 & 0 & 0 \\
\hline \multicolumn{7}{|l|}{ Mealtime component assessed } \\
\hline \multicolumn{7}{|l|}{ Food quality } \\
\hline Home-cooked meal & & & 2 & & & \\
\hline Vegetables at meal & & & 3 & & & \\
\hline Fast food (takeout or in restaurant) & & & 7 & & & \\
\hline \multicolumn{7}{|l|}{ Parental modeling } \\
\hline Direct: model healthy eating & & 9 & & & & \\
\hline Indirect: no special meal for child & & 3 & & & & \\
\hline \multicolumn{7}{|l|}{ Atmosphere } \\
\hline Expert rating of atmosphere & & & & 5 & & \\
\hline Parent report of atmosphere & & & & 4 & & \\
\hline \multicolumn{7}{|l|}{ Duration of meals } \\
\hline Objective (minutes) & & & & & & 4 \\
\hline Subjective (mealtimes are a rush) & & & & & & 1 \\
\hline \multicolumn{7}{|l|}{ Controlled for SES } \\
\hline Yes & 7 & 5 & 3 & 1 & 3 & 1 \\
\hline No & 9 & 7 & 9 & 8 & 4 & 4 \\
\hline
\end{tabular}

Note. $k$ represents the number of studies. TV = television off; $\mathrm{MO}=$ parental modeling; QU $=$ food quality; AT = atmosphere; IN = children's involvement; $\mathrm{DU}=$ duration; $\mathrm{BMI}=$ body mass index; $\mathrm{SES}=$ socioeconomic status.

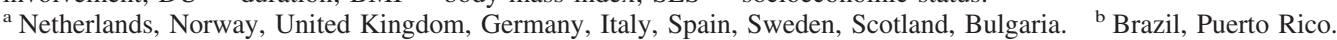

\section{Association Between Components of Family Meal and Children's Nutritional Health}

The following components were significantly associated with better nutritional health: turning the TV off $(r=.09,95 \%$ CI [.05, .13]), parental modeling of healthy eating habits $(r=.12,95 \% \mathrm{CI}$ $[.08, .16])$, higher food quality $(r=.12,95 \% \mathrm{CI}[.07, .17])$, a positive mealtime atmosphere $(r=.13,95 \%$ CI $[.06, .20])$, involvement of children in meal preparation $(r=.08,95 \%$ CI [.04, $.13])$, and longer meal duration $(r=.20,95 \%$ CI $[.09, .29])$. Heterogeneity was large $(46 \%-84 \%)$ and significant in all components. Table 2 summarizes statistical details of the metaanalyses, and Figure 2 shows corresponding forest plots.

\section{Publication Bias}

Funnel plots for TV off, parental modeling, and children's involvement were roughly symmetrical. The plots for food quality, atmosphere, and meal duration were slightly skewed; however, the adjusted effect sizes were still significant when suspected missing studies were imputed. Therefore, there does not seem to be a serious threat of publication bias (Rothstein, Sutton, \& Borenstein, 2005). Statistical details and corresponding funnel plots with trim and filled effect sizes can be found in Figure S1 in the online supplemental materials.

\section{Moderators}

For components assessed in more than 10 studies, age of the target population (children vs. adolescents), outcome type (BMI vs. diet quality), and SES (controlled vs. not controlled for SES) were tested as potential moderators. Although studies investigating children reported higher effect sizes than did studies investigating adolescents on the descriptive level, the age of the target population was not a significant moderator (Figure S2 in 
Table 2

Meta-Analyses and Moderator Analyses With Subgroups

\begin{tabular}{|c|c|c|c|c|c|}
\hline $\begin{array}{l}\text { Mealtime component, moderator, } \\
\text { and subgroups }\end{array}$ & $r$ & {$[95 \% \mathrm{CI}]$} & $Q M$ & $\begin{array}{l}\text { Overall effect size } \\
\quad r[95 \% \mathrm{CI}]\end{array}$ & $I^{2}$ \\
\hline TV off $(k=16)$ & & & & $.09[.05, .13]$ & $68 \%$ \\
\hline \multicolumn{6}{|l|}{ Outcome } \\
\hline Diet quality & .11 & {$[.07, .14]$} & 2.85 & & \\
\hline BMI & .05 & {$[-.01, .11]$} & & & \\
\hline \multicolumn{6}{|l|}{ Age } \\
\hline Children & .10 & {$[.05, .15]$} & .73 & & \\
\hline Adolescents & .07 & {$[.01, .13]$} & & & \\
\hline \multicolumn{6}{|l|}{ SES } \\
\hline Controlled & .09 & {$[.03, .15]$} & .00 & & \\
\hline Not controlled & .09 & {$[.04, .14]$} & & & \\
\hline Parental modeling $(k=12)$ & & & & $.12[.08, .16]$ & $68 \%$ \\
\hline \multicolumn{6}{|l|}{ Outcome } \\
\hline Diet quality & .12 & {$[.08, .17]$} & 1.31 & & \\
\hline BMI & .07 & {$[-.01, .15]$} & & & \\
\hline \multicolumn{6}{|l|}{ Age } \\
\hline Children & .13 & {$[.09, .17]$} & 1.99 & & \\
\hline Adolescents & .07 & {$[.00, .14]$} & & & \\
\hline \multicolumn{6}{|l|}{ SES } \\
\hline Controlled & .10 & {$[.04, .17]$} & .30 & & \\
\hline Not controlled & .13 & {$[.08, .18]$} & & & \\
\hline Food quality $(k=12)$ & & & & $.12[.07, .17]$ & $82 \%$ \\
\hline \multicolumn{6}{|l|}{ Outcome } \\
\hline Diet quality & .17 & {$[.08, .25]$} & 2.00 & & \\
\hline BMI & .10 & {$[.04, .15]$} & & & \\
\hline \multicolumn{6}{|l|}{ Age } \\
\hline Children & .14 & {$[.05, .23]$} & .20 & & \\
\hline Adolescents & .12 & {$[.05, .18]$} & & & \\
\hline \multicolumn{6}{|l|}{ SES } \\
\hline Controlled & .16 & {$[.06, .25]$} & .62 & & \\
\hline Not controlled & .11 & {$[.05, .17]$} & & & \\
\hline Atmosphere $(k=9)$ & & & & $.13[.06, .20]$ & $83 \%$ \\
\hline \multicolumn{6}{|l|}{ Outcome } \\
\hline Diet quality & .09 & {$[-.01, .18]$} & & & \\
\hline BMI & .15 & {$[.04, .26]$} & & & \\
\hline \multicolumn{6}{|l|}{ Age } \\
\hline Children & .14 & {$[.05, .23]$} & & & \\
\hline Adolescents & .12 & {$[.00, .24]$} & & & \\
\hline \multicolumn{6}{|l|}{ SES $^{\mathrm{a}}$} \\
\hline \multicolumn{6}{|l|}{ Controlled } \\
\hline \multicolumn{6}{|l|}{ Not controlled } \\
\hline Children's involvement $(k=7)$ & & & & $.08[.04, .13]$ & $84 \%$ \\
\hline \multicolumn{6}{|l|}{ Outcome $^{\mathrm{a}}$} \\
\hline \multicolumn{6}{|l|}{ Diet quality } \\
\hline \multicolumn{6}{|l|}{ BMI } \\
\hline \multicolumn{6}{|l|}{ Age } \\
\hline Children & .07 & {$[-.01, .15]$} & & & \\
\hline Adolescents & .10 & {$[.03, .16]$} & & & \\
\hline \multicolumn{6}{|l|}{ SES } \\
\hline Controlled & .11 & {$[.04, .19]$} & & & \\
\hline Not controlled & .07 & {$[.01, .12]$} & & & \\
\hline Duration of meals $(k=5)^{\mathrm{a}}$ & & & & $.20[.09, .29]$ & $46 \%$ \\
\hline
\end{tabular}

Note. Results from mixed effects models. Moderator analyses were calculated for only mealtime building blocks examined in at least 10 studies. $r$ is the correlation coefficient; $Q M$ is the $Q M$ test of moderators with $c-$ 1 degrees of freedom, where $c$ is the number of categories in the moderator variable; $I^{2}$ is the heterogeneity index; and $k$ is the number of samples. $\mathrm{CI}=$ confidence interval; $\mathrm{BMI}=$ body mass index; $\mathrm{SES}=$ socioeconomic status.

${ }^{a}$ Given the low number of studies per subgroup $(k<2)$, pooled effect sizes were not calculated.

the online supplemental materials shows the distribution of effect sizes across all components separately for adolescents and children). In a similar way, studies assessing diet quality reported higher effect sizes than did studies assessing BMI for most components (see Table 2 and Figures S3 and S4 in the online supplemental materials). However, outcome type was not a significant moderator. SES was not a significant moderator of the relationship between components and children's nutritional health; pooled effect sizes did not differ substantially between the two categories. 
$\mathrm{TV}$ off $(\mathrm{N}=14,298)$

Coon et al., 2001

Horodynski et al., 2010

Wenhold \& Harrison, 2018

Reos et al., 2014

Petty et al., 2013

Petty et al., 201

Serrano et al, 2014

Fitzpatrick et al., 2007

Pearson, 2017

Stephens et al., 201

Goldman et al., 2012

Hauser et al., 2014

Santiago-Torres et al., 2014

Larson et al., 2013

van Zutphen et al., 2006

Weighted mean effect size for mealtime component

Parental modeling $(\mathrm{N}=10,760)$

Harris \& Ramsey, 2015

Skafida, 2013

Frankel et al, 2018

Goldman et al., 2012

Sweetman et al., 201

Draxten et al., 2014

Vereecken et al., 2004

Stephens et al., 2011

Murashima et al., 2011

Melbye et al., 2013

Weighted mean effect size for mealtime component

Food quality $(\mathrm{N}=9,998)$

Trofholz et al, 2017

Ayala et al., 2007

Fulkerson et al., 2011

Appelhans et al., 2014

Chan \& Sobal, 2011

Ferran-Alexander, 2012

Ayala et al., 2008

Arcan et al., 2007

MacFarlane et al., 2009

Larson et al., 2013

Babajafari et al., 2011

Weighted mean effect size for mealtime component

Atmosphere $(\mathrm{N}=7,655)$

Berge et al., 2014

Berge et al., 2013

Fiese et al., 2012

Jacobs \& Fiese, 2007

Jacobs \& Fiese, 2007

de Wit, 2015

Bergmeier et al., 2016

Weighted mean effect size for mealtime component

Involvement $(\mathrm{N}=14,268)$

Leech et al., 2014

Berge et al., 2017

Chu et al., 2013

de Jong et al., 2015

Spurrier et al., 2008

Melbye et al., 2013

Weighted mean effect size for mealtime component

Duration $(\mathrm{N}=2,666)$

Jacobs \& Fiese, 2007
Berkowitz et al., 2010

Berge et al., 2014

Fiese et al., 20

Skafida, 2013

Weighted mean effect size for mealtime component

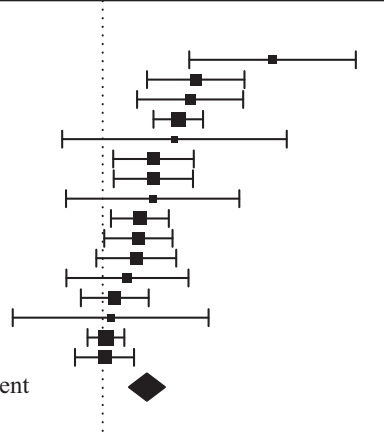

0.33 [ $0.17,0.47$

$0.19[0.09,0.28$

$0.15[0.10,0.20$

$0.14[-0.08,0.36$

$0.10[0.02,0.18$

$0.10[-0.07,0.27$

$0.08[0.02,0.13$

$0.07[0.00,0.14$

0.07 [ $-0.01,0.15$

$0.05[-0.07,0.17$

$0.02[-0.04,0.09$

$0.02[-0.18,0.21$

$0.01-0.03,0.04$

$0.09[0.05,0.13]$

$0.19[0.05,0.32$

$0.18[0.14,0.22$

$0.170 .07,0.26$

0.14 [ $0.04,0.23$

$0.14[-0.02,0.29$

$0.13[0.05,0.20$

$0.11[0.05,0.18$

$0.11-0.04,0.18$

$0.00[-0.08,0.08$

$0.12[0.08,0.15]$

$0.29[0.11,0.44$
$0.28[0.16,0.38$

0.21 [ $0.14,0.27$

0.14 [ $0.01,0.26$

$0.14[-0.03,0.30$

$0.13[-0.15,0.39$

$0.10[-0.04,0.24$

$0.10[0.04,0.16$

$0.09[-0.02,0.19$

$0.03[-0.02,0.06$

$0.03[0.00,0.05]$

$0.12[0.07,0.17]$

$0.34[0.13,0.53$ $0.26[-0.16,0.60$ 0.22 [0.04, 0.38 $0.17[-0.11,0.43$ $0.11[0.03,0.19$ $0.11[0.08,0.13$ $0.06[-0.16,0.27$ $0.00[-0.03,0.04]$

$0.13[0.06,0.19]$

$0.17[0.04,0.29$ $0.12[0.09,0.16$ $0.12[0.09,0.15$ $0.08[-0.04,0.19$ $0.02[-0.06,0.10$ $0.01[-0.02,0.03$ $0.08[0.04,0.13]$

$0.34[0.08,0.56$ $0.29[0.04,0.51$ $0.26[0.04,0.46$ $0.11[0.07,0.15$ $0.20[0.09,0.29]$

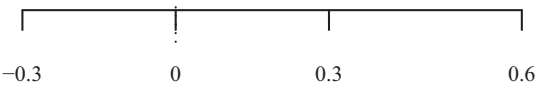

Less nutritionally healthy More nutritionally healthy

Figure 2. Forest plot showing the distribution of effect sizes for each mealtime component.

\section{Quality Assessment}

Study quality was not a significant moderator (fast food: $Q M=$ 2.60, $p=.108$; role modeling: $Q M=.31, p=.575$; $\mathrm{TV}$ off: $Q M=.00, p=.98)$.

\section{Discussion}

This systematic review and meta-analysis identified six social, environmental, and behavioral components of family mealtime that may help to explain why frequent family meals foster chil- 
dren's nutritional health: turning the TV off at mealtimes, better food quality, parental modeling of healthy eating, a positive atmosphere, children's involvement in meal preparation, and longer meal duration. The effect sizes of family meal components were small. How a family eats together thus seems to be at least equally as important as how often. The results suggest that the association between the mealtime components and nutritional health holds above and beyond effects of SES and age. With the exception of studies examining atmosphere as a mealtime component, on a descriptive level, studies with diet quality as outcome showed higher effect sizes compared to studies with BMI as outcome. However, this effect was not significant. It is possible that the statistical power to detect moderator effects was insufficient due to the small numbers of studies included.

Because this meta-analysis aggregated cross-sectional studies, we cannot determine causality. Nevertheless, the findings, in conjunction with other studies on family systems and eating behavior, suggest that the six identified components of family meals may be beneficial for children's nutritional health. Research has shown that families with normal-weight children have higher levels of healthy family functioning compared to families with overweight children (Turner, Rose, \& Cooper, 2005). Thus, gathering around the table without distraction from TV, cooking and eating fresh food and involving the child in the process, having positive social interactions, role modeling, and taking time to eat may improve family cohesion and climate.

The findings suggest that sharing family meals according to the six components may increase family functioning, which in turn fosters positive health behavior in children. Additional mechanisms may operate more directly within the mealtime situation and influence children's eating behavior. Such possible mechanisms for each of the six components include the following: Watching TV while eating, for example, impairs the capacity to monitor food intake and attend to satiety cues (Blass et al., 2006). The finding that parental modeling is linked to better nutritional health in children is supported by experimental results showing that children are more likely to eat a new food if an adult role model eats the same type of food (Addessi, Galloway, Visalberghi, \& Birch, 2005). The association between a positive mealtime atmosphere and better nutritional health may be explained by the child's being less likely to engage in emotional eating (Wildermuth, Mesman, \& Ward, 2013). It is interesting that atmosphere was the only mealtime component for which (on a descriptive level) studies with BMI as outcome showed higher effect sizes compared to studies with diet quality as outcome. A negative mealtime atmosphere might be an indicator of a more general negative family climate, which, according to family systems theory, is a potential risk factor for childhood obesity (Turner et al., 2005). Children who experience self-agency and participatory decision-making in the context of meal preparation may develop a greater interest in nutrition (L. Hill, Casswell, Maskill, Jones, \& Wyllie, 1998) and a greater sense of self-efficacy for healthy eating (Chu et al., 2013). Longer meals are associated with lower BMI and better diet quality. It is possible that people who take more time eat at a slower rate permit a sense of satiety to kick in before they have finished (Berkowitz et al., 2010). In addition, longer mealtimes may result in longer intermeal satiety (Andrade, Kresge, Teixeira, Baptista, \& Melanson, 2012).

This study has limitations. First, all studies were observational. Confounding variables and alternative explanations cannot be ruled out. For example, the mealtime components might be the result, not the cause, of more positive family functioning and healthier family life. Second, heterogeneity between studies was high. Beyond the moderators investigated, other potential sources of heterogeneity include variability in the definition and operationalization of family mealtimes (e.g., dinner vs. main meal) and variability in how key variables were measured. Due to the limited number of studies to date and the inconsistency across many variables, it was not possible to analyze to what extent these differences mattered. One goal of this meta-analysis was to systematically describe factors such as the high variability across definitions and measures. This provides the basis for eventually reaching scientific consensus on definitions and measures and, consequently, reducing heterogeneity between studies in the future. Third, observed effects are small. Except for meal duration, the effect sizes of the mealtime components are below the generally recommended threshold for a "practically" significant effect $(r=.20$; Ferguson, 2009). However, it is worth keeping in mind that effect sizes in the field of obesity and diet are usually small, because they are influenced by an interplay of environmental, biological, and behavioral factors. Furthermore, even small effect sizes can have a large public health impact. For example, a small weight loss substantially reduces cardiovascular risk factors (Reinehr et al., 2016). The effect sizes we found for the six family mealtime components are in the same range as the effect sizes reported in large observational studies of obesity risk factors, such as skipping breakfast (e.g., the meta-analysis by de la Hunty, Gibson, \& Ashwell, 2013). A preregistered protocol and screening $100 \%$ of the studies by two independent raters (instead of 30\%) could have improved the quality of this meta-analysis even further.

Evidence quality ratings such as GRADE (Grading of Recommendations Assessment, Development, and Evaluation; Guyatt, Oxman, Schünemann, Tugwell, \& Knottnerus, 2011) suggest that the quality of evidence for clinical practice is currently very low (due to observational designs, high heterogeneity [high inconsistency], and significant risk of bias in some of the studies; see Table S3 in the online supplemental materials for details). Taken together, the limitations show that, despite the fast-growing research around family meals, this is a still young field. It is important to note that the goal of this meta-analysis is not to provide evidence for clinical practice but to systematize the growing field of family meal research and provide a basis for more coherent, experimental research. The latter will lead to better evidence for clinical practice in the future.

The next step will be to conduct randomized control studies. For example, it has already been shown that a distracting noise during the family meal can decrease children's consumption of healthy foods (Fiese, Jones, \& Jarick, 2015). Future studies should focus on specific components, ideally using longitudinal designs and standardized constructs and measures. Also, experimental studies should explore the type of relationship between the mealtime components and children's nutritional health. For meal duration, a U-shaped relationship with both very short and very long meal durations negatively impacting nutritional health could emerge. For other family mealtime components, a linear relationship as assumed in this meta-analysis seems more likely, with, for instance, more role modeling bringing about more beneficial effects.

Understudied mealtime components such as the location of the family meal (Skafida, 2013), the family members present at the 
table (Sweetman, McGowan, Croker, \& Cooke, 2011), or the usage of electronic devices other than TV (Berge et al., 2014) also warrant future research, as do dependencies between components. For example, children's involvement in meal preparation may co-occur with higher food quality and less fast food. Future research should further examine to what extent the components can be transferred to other contexts, such as school or kindergarten. One experimental study has already shown that teachers who model dietary behaviors in the same way as parents function as role models during meals (Hendy \& Raudenbush, 2000).

This study has potentially important practical implications. The recommendation that families should eat together more often is widely propagated in the media. The current findings suggest that the beneficial role of family meals may depend substantially on how families eat together. Few intervention studies have examined family meals as a means of addressing childhood obesity. First promising results stem from a randomized control intervention (Fulkerson et al., 2015). In this intervention, components of family mealtimes were manipulated by eliminating electronic devices at mealtimes or promoting positive conversations, which led to a reduction in weight gain. If randomized control studies continue to confirm the positive role of the components examined, these insights should be shared with parents and other architects of children's food environments (e.g., teachers). The mealtime components are nonintrusive, actionable boosting interventions (Dallacker, Mata, \& Hertwig, 2019; Hertwig \& Grüne-Yanoff, 2017); they can be easily communicated, learned, and practiced. This is particularly important because some of the components identified in this meta-analysis are probably in decline because of lifestyle changes such as eating on the go, use of electronic devices during mealtimes, and increasing numbers of dual-earner families (Breaugh \& Frye, 2008; Smith, Ng, \& Popkin, 2013). The success of communicating positive mealtime components may depend on the finances and time available to commit to the endeavor (Johnson et al., 2010). A pluralistic approach that also targets the convenience and costs of unhealthy and healthy foods (taxes vs. subsidies; Powell \& Chaloupka, 2009) may thus be promising.

Given the diversity of modern family structures, the present results should be interpreted in the light of gender equity goals in domestic and workplace demands. Interventions implementing the positive components of family meals should consider these factors. For example, some of the components may generalize across other social meal contexts, such as school canteens. Additionally, digitalization is making office hours and locations more flexible, and some employers now provide cafeterias in which families can eat together.

\section{References}

References marked with an asterisk indicate studies included in the meta-analysis.

Addessi, E., Galloway, A. T., Visalberghi, E., \& Birch, L. L. (2005). Specific social influences on the acceptance of novel foods in 2-5-yearold children. Appetite, 45, 264-271. http://dx.doi.org/10.1016/j.appet 2005.07.007

Agarwald, A., Guyatt, G., \& Busse, J. (2019). Methods commentary: Risk of bias in cross-sectional surveys of attitudes and practices. Retrieved from https://www.evidencepartners.com/resources/methodologicalresources/risk-of-bias-cross-sectional-surveys-of-attitudes-and-practices/
Andrade, A. M., Kresge, D. L., Teixeira, P. J., Baptista, F., \& Melanson, K. J. (2012). Does eating slowly influence appetite and energy intake when water intake is controlled? International Journal of Behavioral Nutrition and Physical Activity, 9, 135. http://dx.doi.org/10.1186/14795868-9-135

Appelhans, B. M., Milliron, B. J., Woolf, K., Johnson, T. J., Pagoto, S. L., Schneider, K. L., . . . Ventrelle, J. C. (2012). Socioeconomic status, energy cost, and nutrient content of supermarket food purchases. American Journal of Preventive Medicine, 42, 398-402. http://dx.doi.org/10 .1016/j.amepre.2011.12.007

*Appelhans, B. M., Waring, M. E., Schneider, K. L., \& Pagoto, S. L. (2014). Food preparation supplies predict children's family meal and home-prepared dinner consumption in low-income households. Appetite, 76, 1-8. http://dx.doi.org/10.1016/j.appet.2014.01.008

*Arcan, C., Neumark-Sztainer, D., Hannan, P., van den Berg, P., Story, M., \& Larson, N. (2007). Parental eating behaviours, home food environment and adolescent intakes of fruits, vegetables and dairy foods: Longitudinal findings from Project EAT. Public Health Nutrition, 10, $1257-$ 1265. http://dx.doi.org/10.1017/S1368980007687151

Aune, D., Giovannucci, E., Boffetta, P., Fadnes, L. T., Keum, N., Norat, T., . . Tonstad, S. (2017). Fruit and vegetable intake and the risk of cardiovascular disease, total cancer and all-cause mortality-A systematic review and dose-response meta-analysis of prospective studies. International Journal of Epidemiology, 46, 1029-1056. http://dx.doi org/10.1093/ije/dyw319

*Ayala, G. X., Baquero, B., Arredondo, E. M., Campbell, N., Larios, S., \& Elder, J. P. (2007). Association between family variables and Mexican American children's dietary behaviors. Journal of Nutrition Education and Behavior, 39, 62-69. http://dx.doi.org/10.1016/j.jneb.2006.08.025

*Ayala, G. X., Rogers, M., Arredondo, E. M., Campbell, N. R., Baquero, B., Duerksen, S. C., \& Elder, J. P. (2008). Away-from-home food intake and risk for obesity: Examining the influence of context. Obesity, 16, 1002-1008. http://dx.doi.org/10.1038/oby.2008.34

*Babajafari, S., Marks, G. C., Mamun, A. A., O'Callaghan, M. J., \& Najman, J. M. (2011). Family food behaviours and adolescents' overweight status: A mother-offspring link study. Iranian Red Crescent Medical Journal, 13, 783-794.

Becker, B. J., \& Wu, M.-J. (2007). The synthesis of regression slopes in meta-analysis. Statistical Science, 22, 414-429. http://dx.doi.org/10.1214/ 07-STS243

*Berge, J. M., Jin, S. W., Hannan, P., \& Neumark-Sztainer, D. (2013). Structural and interpersonal characteristics of family meals: Associations with adolescent body mass index and dietary patterns. Journal of the Academy of Nutrition and Dietetics, 113, 816-822. http://dx.doi.org/ 10.1016/j.jand.2013.02.004

*Berge, J. M., MacLehose, R. F., Larson, N., Laska, M., \& NeumarkSztainer, D. (2016). Family food preparation and its effects on adolescent dietary quality and eating patterns. Journal of Adolescent Health, 59, 530-536. http://dx.doi.org/10.1016/j.jadohealth.2016.06.007

*Berge, J. M., Rowley, S., Trofholz, A., Hanson, C., Rueter, M., MacLehose, R. F., \& Neumark-Sztainer, D. (2014). Childhood obesity and interpersonal dynamics during family meals. Pediatrics, 134, 923-932. http://dx.doi.org/10.1542/peds.2014-1936

*Berge, J. M., Wall, M., Larson, N., Forsyth, A., Bauer, K. W., \& Neumark-Sztainer, D. (2014). Youth dietary intake and weight status: Healthful neighborhood food environments enhance the protective role of supportive family home environments. Health \& Place, 26, 69-77. http://dx.doi.org/10.1016/j.healthplace.2013.11.007

*Bergmeier, H., Aksan, N., McPhie, S., Fuller-Tyszkiewicz, M., Baur, L., Milgrom, J., . . . Skouteris, H. (2016). Mutually responsive orientation A novel observational assessment of mother-child mealtime interactions. Appetite, 105, 400-409. http://dx.doi.org/10.1016/j.appet.2016.06.019

Berkowitz, R. I., Moore, R. H., Faith, M. S., Stallings, V. A., Kral, T. V. E., \& Stunkard, A. J. (2010). Identification of an obese eating style 
in 4-year-old children born at high and low risk for obesity. Obesity, 18, 505-512. http://dx.doi.org/10.1038/oby.2009.299

*Blanques Petty, M. L., Escrivão, M. A. M. S., \& Souza, A. A. (2013). Preliminary validation of the Parent Mealtime Action Scale and its association with food intake in children from São Paulo, Brazil. Appetite, 62, 166-172. http://dx.doi.org/10.1016/j.appet.2012.11.024

Blass, E. M., Anderson, D. R., Kirkorian, H. L., Pempek, T. A., Price, I., \& Koleini, M. F. (2006). On the road to obesity: Television viewing increases intake of high-density foods. Physiology \& Behavior, 88, 597-604. http://dx.doi.org/10.1016/j.physbeh.2006.05.035

Bombak, A. (2014). Obesity, health at every size, and public health policy. American Journal of Public Health, 104(2), e60-e67. http://dx.doi.org/ 10.2105/AJPH.2013.301486

Borenstein, M., Hedges, L. V., Higgins, J. P. T., \& Rothstein, H. R. (2009). Introduction to meta-analysis. http://dx.doi.org/10.1002/9780470743386

Breaugh, J. A., \& Frye, N. K. (2008). Work-family conflict: The importance of family-friendly employment practices and family-supportive supervisors. Journal of Business and Psychology, 22, 345-353. http:// dx.doi.org/10.1007/s10869-008-9081-1

Card, N. (2011). Applied meta-analysis for social science research. New York, NY: Guilford Press.

*Chan, J. C., \& Sobal, J. (2011). Family meals and body weight. Analysis of multiple family members in family units. Appetite, 57, 517-524. http://dx.doi.org/10.1016/j.appet.2011.07.001

*Chan, R., Yeung, S., Leung, C., Lo, S. K., \& Tsang, S. (2018). Family factors and fruit and vegetable consumption in Chinese preschool children living in Hong Kong. Journal of Children's Services, 13, 122-133. http://dx.doi.org/10.1108/JCS-08-2017-0033

Chu, Y. L., Farmer, A., Fung, C., Kuhle, S., Storey, K. E., \& Veugelers, P. J. (2013). Involvement in home meal preparation is associated with food preference and self-efficacy among Canadian children. Public Health $\mathrm{Nu}$ trition, 16, 108-112. http://dx.doi.org/10.1017/S1368980012001218

${ }^{*}$ Chu, Y. L., Storey, K. E., \& Veugelers, P. J. (2014). Involvement in meal preparation at home is associated with better diet quality among Canadian children. Journal of Nutrition Education and Behavior, 46, 304308. http://dx.doi.org/10.1016/j.jneb.2013.10.003

"Coon, K. A., Goldberg, J., Rogers, B. L., \& Tucker, K. L. (2001). Relationships between use of television during meals and children's food consumption patterns. Pediatrics, 107(1), e7. http://dx.doi.org/10 .1542/peds.107.1.e7

Cooper, H., Hedges, L. V., \& Valentine, J. C. (Eds.). (2009). The handbook of research synthesis and meta-analysis. New York, NY: Russell Sage Foundation.

Cox, M. J., \& Paley, B. (1997). Families as systems. Annual Review of Psychology, 48, 243-267. http://dx.doi.org/10.1146/annurev.psych.48.1 .243

Dallacker, M., Hertwig, R., \& Mata, J. (2018). The frequency of family meals and nutritional health in children: A meta-analysis. Obesity Reviews, 19, 638-653. http://dx.doi.org/10.1111/obr.12659

Dallacker, M., Mata, J., \& Hertwig, R. (2019). Toward simple eating rules for the land of plenty. In R. Hertwig, T. J. Pleskac, T. Pachur, \& The Center for Adaptive Rationality. (Eds.), Taming uncertainty (pp. 111130). Cambridge, MA: MIT Press

de Castro, J. M. (1994). Family and friends produce greater social facilitation of food intake than other companions. Physiology \& Behavior, 56, 445-455. http://dx.doi.org/10.1016/0031-9384(94)90286-0

*de Jong, E., Visscher, T. L., HiraSing, R. A., Seidell, J. C., \& Renders, C. M. (2015). Home environmental determinants of children's fruit and vegetable consumption across different SES backgrounds. Pediatric Obesity, 10, 134-140. http://dx.doi.org/10.1111/ijpo.243

de la Hunty, A., Gibson, S., \& Ashwell, M. (2013). Does regular breakfast cereal consumption help children and adolescents stay slimmer? A systematic review and meta-analysis. Obesity Facts, 6, 70-85. http://dx .doi.org/10.1159/000348878 *de Wit, J. B., Stok, F. M., Smolenski, D. J., de Ridder, D. D., de Vet, E., Gaspar, T., . . Luszczynska, A. (2015). Food culture in the home environment: Family meal practices and values can support healthy eating and self-regulation in young people in four European countries. Applied Psychology: Health and Well-Being, 7, 22-40. http://dx.doi.org/ 10.1111/aphw.12034

*Draxten, M., Fulkerson, J. A., Friend, S., Flattum, C. F., \& Schow, R. (2014). Parental role modeling of fruits and vegetables at meals and snacks is associated with children's adequate consumption. Appetite, 78, 1-7. http://dx.doi.org/10.1016/j.appet.2014.02.017

Duval, S., \& Tweedie, R. (2000). Trim and fill: A simple funnel-plot-based method of testing and adjusting for publication bias in meta-analysis. Biometrics, 56, 455-463. http://dx.doi.org/10.1111/j.0006-341X.2000 .00455. $\mathrm{x}$

Ferguson, C. J. (2009). An effect size primer: A guide for clinicians and researchers. Professional Psychology: Research and Practice, 40, 532 538. http://dx.doi.org/10.1037/a0015808

*Ferran-Alexander, M. A. (2012). Chronic stress and obesity in children (Doctoral dissertation). Available from ProQuest Dissertations and Theses database. (UMI No. 3484426)

*Fiese, B. H., Hammons, A., \& Grigsby-Toussaint, D. (2012). Family mealtimes: A contextual approach to understanding childhood obesity. Economics and Human Biology, 10, 365-374. http://dx.doi.org/10.1016/ j.ehb.2012.04.004

Fiese, B. H., Jones, B. L., \& Jarick, J. M. (2015). Family mealtime dynamics and food consumption: An experimental approach to understanding distractions. Couple and Family Psychology: Research and Practice, 4, 199-211. http://dx.doi.org/10.1037/cfp0000047

Fiese, B. H., \& Schwartz, M. (2008). Reclaiming the family table: Mealtimes and child health and wellbeing. Social Policy Report, 22, 4 Retrieved from http://eric.ed.gov/?id=ED521697

*FitzPatrick, E., Edmunds, L. S., \& Dennison, B. A. (2007). Positive effects of family dinner are undone by television viewing. Journal of the American Dietetic Association, 107, 666-671. http://dx.doi.org/10.1016/j.jada.2007 .01 .014

*Frankel, L. A., Powell, E., \& Jansen, E. (2018). The relationship between structure-related food parenting practices and children's heightened levels of self-regulation in eating. Childhood Obesity, 14, 81-88. http://dx doi.org/10.1089/chi.2017.0164

"Fulkerson, J. A., Farbakhsh, K., Lytle, L., Hearst, M. O., Dengel, D. R. Pasch, K. E., \& Kubik, M. Y. (2011). Away-from-home family dinner sources and associations with weight status, body composition, and related biomarkers of chronic disease among adolescents and their parents. Journal of the American Dietetic Association, 111, 1892-1897. http://dx.doi.org/10.1016/j.jada.2011.09.035

Fulkerson, J. A., Friend, S., Flattum, C., Horning, M., Draxten, M., Neumark-Sztainer, D., . . Kubik, M. Y. (2015). Promoting healthfu family meals to prevent obesity: HOME Plus, a randomized controlled trial. International Journal of Behavioral Nutrition and Physical Activity, 12, 154. http://dx.doi.org/10.1186/s12966-015-0320-3

Fulkerson, J. A., Larson, N., Horning, M., \& Neumark-Sztainer, D. (2014). A review of associations between family or shared meal frequency and dietary and weight status outcomes across the lifespan. Journal of Nutrition Education and Behavior, 46, 2-19. http://dx.doi.org/10.1016/ j.jneb.2013.07.012

*Goldman, R. L., Radnitz, C. L., \& McGrath, R. E. (2012). The role of family variables in fruit and vegetable consumption in pre-school children. Journal of Public Health Research, 1(2), e22. http://dx.doi.org/10 4081/jphr.2012.e22

Guyatt, G. H., Oxman, A. D., Schünemann, H. J., Tugwell, P., \& Knottnerus, A. (2011). GRADE guidelines: A new series of articles in the Journal of Clinical Epidemiology. Journal of Clinical Epidemiology, 64, 380-382. http://dx.doi.org/10.1016/j.jclinepi.2010.09.011 
Hales, C. M., Carroll, M. D., Fryar, C. D., \& Ogden, C. L. (2017). Prevalence of obesity among adults and youth: United States, 20152016 (NCHS Data Brief No. 288). Retrieved from Centers for Disease Control and Prevention website: https://stacks.cdc.gov/view/cdc/49223

*Harris, T. S., \& Ramsey, M. (2015). Paternal modeling, household availability, and paternal intake as predictors of fruit, vegetable, and sweetened beverage consumption among African American children. Appetite, 85, 171-177. http://dx.doi.org/10.1016/j.appet.2014.11.008

"Hauser, S. I., Economos, C. D., Nelson, M. E., Goldberg, J. P., Hyatt, R. R., Naumova, E. N., . . . Must, A. (2014). Household and family factors related to weight status in first through third graders: A crosssectional study in Eastern Massachusetts. BMC Pediatrics, 14, 167. http://dx.doi.org/10.1186/1471-2431-14-167

Hebestreit, A., Intemann, T., Siani, A., De Henauw, S., Eiben, G., Kourides, Y. A., . . . Pigeot, I. (2017). Dietary patterns of European children and their parents in association with family food environment: Results from the I.Family study. Nutrients, 9, 126-142. http://dx.doi.org/10 $.3390 /$ nu9020126

Hendy, H. M., \& Raudenbush, B. (2000). Effectiveness of teacher modeling to encourage food acceptance in preschool children. Appetite, 34, 61-76. http://dx.doi.org/10.1006/appe.1999.0286

Hertwig, R., \& Grüne-Yanoff, T. (2017). Nudging and boosting: Steering or empowering good decisions. Perspectives on Psychological Science, 12, 973-986. http://dx.doi.org/10.1177/1745691617702496

Hill, J. O., Wyatt, H. R., \& Peters, J. C. (2012). Energy balance and obesity. Circulation, 126, 126-132. http://dx.doi.org/10.1161/ CIRCULATIONAHA.111.087213

Hill, L., Casswell, S., Maskill, C., Jones, S., \& Wyllie, A. (1998). Fruit and vegetables as adolescent food choices in New Zealand. Health Promotion International, 13, 55-65. http://dx.doi.org/10.1093/heapro/13.1.55

*Horodynski, M. A., Stommel, M., Brophy-Herb, H. E., \& Weatherspoon, L. (2010). Mealtime television viewing and dietary quality in lowincome African American and Caucasian mother-toddler dyads. Maternal and Child Health Journal, 14, 548-556. http://dx.doi.org/10.1007/ s10995-009-0501-2

Hruby, A., Manson, J. E., Qi, L., Malik, V. S., Rimm, E. B., Sun, Q., . . . Hu, F. B. (2016). Determinants and consequences of obesity. American Journal of Public Health, 106, 1656-1662. http://dx.doi.org/10.2105/ AJPH.2016.303326

Huedo-Medina, T. B., Sánchez-Meca, J., Marín-Martínez, F., \& Botella, J. (2006). Assessing heterogeneity in meta-analysis: $Q$ statistic or $I^{2}$ index? Psychological Methods, 11, 193-206. http://dx.doi.org/10.1037/1082989X.11.2.193

Hunter, J. E., \& Schmidt, F. L. (2004). Methods of meta-analysis: Correcting error and bias in research findings. http://dx.doi.org/10.4135/ 9781412985031

Jackson, D., \& Turner, R. (2017). Power analysis for random-effects meta-analysis. Research Synthesis Methods, 8, 290-302. http://dx.doi . org/10.1002/jrsm. 1240

*Jacobs, M. P., \& Fiese, B. H. (2007). Family mealtime interactions and overweight children with asthma: Potential for compounded risks? Journal of Pediatric Psychology, 32, 64-68. http://dx.doi.org/10.1093/jpepsy/js1026

Johnson, B. T., Redding, C. A., DiClemente, R. J., Mustanski, B. S., Dodge, B., Sheeran, P., . . . Fishbein, M. (2010). A network-individualresource model for HIV prevention. AIDS and Behavior, 14(Suppl. 2), 204-221. http://dx.doi.org/10.1007/s10461-010-9803-Z

Kitzman-Ulrich, H., Wilson, D. K., St. George, S. M., Lawman, H., Segal, M., \& Fairchild, A. (2010). The integration of a family systems approach for understanding youth obesity, physical activity, and dietary programs. Clinical Child and Family Psychology Review, 13, 231-253. http://dx .doi.org/10.1007/s10567-010-0073-0

*Larson, N., Eisenberg, M. E., Berge, J. M., Arcan, C., \& NeumarkSztainer, D. (2015). Ethnic/racial disparities in adolescents' home food environments and linkages to dietary intake and weight status. Eating Behaviors, 16, 43-46. http://dx.doi.org/10.1016/j.eatbeh.2014.10.010

*Larson, N. I., Story, M., Eisenberg, M. E., \& Neumark-Sztainer, D. (2006). Food preparation and purchasing roles among adolescents: Associations with sociodemographic characteristics and diet quality. Journal of the American Dietetic Association, 106, 211-218. http://dx.doi .org/10.1016/j.jada.2005.10.029

"Larson, N. I., Wall, M. M., Story, M. T., \& Neumark-Sztainer, D. R. (2013). Home/family, peer, school, and neighborhood correlates of obesity in adolescents. Obesity, 21, 1858-1869. http://dx.doi.org/10.1002/oby.20360

*Leech, R. M., McNaughton, S. A., Crawford, D. A., Campbell, K. J., Pearson, N., \& Timperio, A. (2014). Family food involvement and frequency of family dinner meals among Australian children aged 10-12 years: Crosssectional and longitudinal associations with dietary patterns. Appetite, 75, 64-70. http://dx.doi.org/10.1016/j.appet.2013.12.021

Light, R. J., Singer, J. D., \& Willet, J. B. (1994). The visual presentation and interpretation of meta-analyses. In H. M. Cooper \& L. V. Hedges (Eds.), The handbook of research synthesis (pp. 215-230). New York, NY: Russel Sage Foundation.

*MacFarlane, A., Cleland, V., Crawford, D., Campbell, K., \& Timperio, A. (2009). Longitudinal examination of the family food environment and weight status among children. International Journal of Pediatric Obesity, 4, 343-352. http://dx.doi.org/10.3109/17477160902846211

Martin-Biggers, J., Spaccarotella, K., Berhaupt-Glickstein, A., Hongu, N., Worobey, J., \& Byrd-Bredbenner, C. (2014). Come and get it! A discussion of family mealtime literature and factors affecting obesity risk. Advances in Nutrition, 5, 235-247. http://dx.doi.org/10.3945/an.113.005116

*Mâsse, L. C., Blanck, H. M., Valente, M., Atienza, A. A., Agurs-Collins, T., Weber, D., \& Yaroch, A. L. (2012). Association between selfreported household practices and body mass index of U.S. children and adolescents, 2005. Preventing Chronic Disease, 9, 110149. http://dx.doi .org/10.5888/pcd9.110149

McCurdy, K., Gorman, K. S., Kisler, T., \& Metallinos-Katsaras, E. (2014). Associations between family food behaviors, maternal depression, and child weight among low-income children. Appetite, 79, 97-105. http:// dx.doi.org/10.1016/j.appet.2014.04.015

*Melbye, E. L., Øgaard, T., \& Øverby, N. C. (2013). Associations between parental feeding practices and child vegetable consumption. Mediation by child cognitions? Appetite, 69, 23-30. http://dx.doi.org/10.1016/ appet.2013.05.005

Moher, D., Liberati, A., Tetzlaff, J., Altman, D. G., \& The PRISMA Group. (2009). Preferred reporting items for systematic reviews and meta-analyses: The PRISMA statement. PLoS Medicine, 6(7), e1000097. http://dx.doi.org/10.1371/journal.pmed.1000097

Morgenstern, M., Sargent, J. D., \& Hanewinkel, R. (2009). Relation between socioeconomic status and body mass index: Evidence of an indirect path via television use. Archives of Pediatrics \& Adolescent Medicine, 163, 731738. http://dx.doi.org/10.1001/archpediatrics.2009.78

*Murashima, M., Hoerr, S. L., Hughes, S. O., \& Kaplowitz, S. (2011). Confirmatory factor analysis of a questionnaire measuring control in parental feeding practices in mothers of Head Start children. Appetite, 56, 594-601. http://dx.doi.org/10.1016/j.appet.2011.01.031

Nagahama, S., Kurotani, K., Pham, N. M., Nanri, A., Kuwahara, K., Dan, M., . . . Mizoue, T. (2014). Self-reported eating rate and metabolic syndrome in Japanese people: Cross-sectional study. British Medical Journal Open, 4, e005241. http://dx.doi.org/10.1136/bmjopen-2014005241

Pearson, N., Biddle, S. J., \& Gorely, T. (2009). Family correlates of fruit and vegetable consumption in children and adolescents: A systematic review. Public Health Nutrition, 12, 267-283. http://dx.doi.org/10.1017/ S1368980008002589

*Pearson, N., Griffiths, P., Biddle, S. J., Johnston, J. P., McGeorge, S., \& Haycraft, E. (2017). Clustering and correlates of screen-time and eating 
behaviours among young adolescents. BMC Public Health, 17, 533. http://dx.doi.org/10.1186/s12889-017-4441-2

Peterson, R. A., \& Brown, S. P. (2005). On the use of beta coefficients in meta-analysis. Journal of Applied Psychology, 90, 175-181. http://dx .doi.org/10.1037/0021-9010.90.1.175

Poti, J. M., \& Popkin, B. M. (2011). Trends in energy intake among U.S. children by eating location and food source, 1977-2006. Journal of the American Dietetic Association, 111, 1156-1164. http://dx.doi.org/10.1016/ j.jada.2011.05.007

Powell, L. M., \& Chaloupka, F. J. (2009). Food prices and obesity: Evidence and policy implications for taxes and subsidies. Milbank Quarterly, 87, 229-257. http://dx.doi.org/10.1111/j.1468-0009.2009.00554.x19298422

Reinehr, T., Lass, N., Toschke, C., Rothermel, J., Lanzinger, S., \& Holl, R. W. (2016). Which amount of BMI-SDS reduction is necessary to improve cardiovascular risk factors in overweight children? Journal of Clinical Endocrinology and Metabolism, 101, 3171-3179. http://dx.doi .org/10.1210/jc.2016-1885

*Roos, E., Pajunen, T., Ray, C., Lynch, C., Kristiansdottir, A. G., Halldorsson, T. I., . . . Yngve, A. (2014). Does eating family meals and having the television on during dinner correlate with overweight? A sub-study of the PRO GREENS project, looking at children from nine European countries. Public Health Nutrition, 17, 2528-2536. http://dx doi.org/10.1017/S1368980013002954

Rosenheck, R. (2008). Fast food consumption and increased caloric intake: A systematic review of a trajectory towards weight gain and obesity risk. Obesity Reviews, 9, 535-547. http://dx.doi.org/10.1111/j.1467-789X.2008 .00477.x

Rothman, K. J. (2008). BMI-related errors in the measurement of obesity. International Journal of Obesity, 32(Suppl. 3), S56-S59. http://dx.doi .org/10.1038/ijo.2008.87

Rothstein, H. R., Sutton, A. J., \& Borenstein, M. (Eds.). (2005). Publication bias in meta-analysis. Prevention, assessment and adjustment. http://dx.doi.org/10.1002/0470870168

Saad, L. (2013). Most U.S. families still routinely dine together at home. Retrieved from http://www.gallup.com/poll/166628/families-routinelydine-together-home.aspx

"Santiago-Torres, M., Adams, A. K., Carrel, A. L., LaRowe, T. L., \& Schoeller, D. A. (2014). Home food availability, parental dietary intake, and familial eating habits influence the diet quality of urban Hispanic children. Childhood Obesity, 10, 408-415. http://dx.doi.org/10.1089/chi 2014.0051

Savage, J. S., Fisher, J. O., \& Birch, L. L. (2007). Parental influence on eating behavior: Conception to adolescence. Journal of Law, Medicine \& Ethics, 35, 22-34. http://dx.doi.org/10.1111/j.1748-720X.2007.00111.x

"Serrano, M., Torres, R., Pérez, C. M., \& Palacios, C. (2014). Social environment factors, diet quality, and body weight in 12-year-old children from four public schools in Puerto Rico. Puerto Rico Health Sciences Journal, 33, 80-87.

"Skafida, V. (2013). The family meal panacea: Exploring how different aspects of family meal occurrence, meal habits and meal enjoyment relate to young children's diets. Sociology of Health \& Illness, 35, 906-923. http://dx.doi.org/10.1111/1467-9566.12007

Smith, L. P., Ng, S. W., \& Popkin, B. M. (2013). Trends in U.S. home food preparation and consumption: Analysis of national nutrition surveys and time use studies from 1965-1966 to 2007-2008. Nutrition Journal, 12, 45. http://dx.doi.org/10.1186/1475-2891-12-45
Spagnola, M., \& Fiese, B. H. (2007). Family routines and rituals: A context for development in the lives of young children. Infants \& Young Children, 20, 284-299. http://dx.doi.org/10.1097/01.IYC.0000290352.32170.5a

*Spurrier, N. J., Magarey, A. A., Golley, R., Curnow, F., \& Sawyer, M. G. (2008). Relationships between the home environment and physical activity and dietary patterns of preschool children: A cross-sectional study. International Journal of Behavioral Nutrition and Physical Activity, 5, 31. http://dx.doi.org/10.1186/1479-5868-5-31

*Stephens, L. D. A., McNaughton, S. A., Crawford, D., MacFarlane, A., \& Ball, K. (2011). Correlates of dietary resilience among socioeconomically disadvantaged adolescents. European Journal of Clinical Nutrition, 65, 1219-1232. http://dx.doi.org/10.1038/ejen.2011.107

Story, M., Neumark-Sztainer, D., \& French, S. (2002). Individual and environmental influences on adolescent eating behaviors. Journal of the American Dietetic Association, 102(3, Suppl.), S40-S51. http://dx.doi .org/10.1016/S0002-8223(02)90421-9

*Sweetman, C., McGowan, L., Croker, H., \& Cooke, L. (2011). Characteristics of family mealtimes affecting children's vegetable consumption and liking. Journal of the American Dietetic Association, 111, 269-273. http://dx.doi.org/10.1016/j.jada.2010.10.050

*Tremblay, L., \& Rinaldi, C. M. (2010). The prediction of preschool children's weight from family environment factors: Gender-linked differences. Eating Behaviors, 11, 266-275. http://dx.doi.org/10.1016/j .eatbeh.2010.07.005

"Trofholz, A. C., Tate, A. D., Draxten, M. L., Rowley, S. S., Schulte, A. K., Neumark-Sztainer, D., . . . Berge, J. M. (2017). What's being served for dinner? An exploratory investigation of the associations between the healthfulness of family meals and child dietary intake. Journal of the Academy of Nutrition and Dietetics, 117, 102-109. http://dx.doi.org/10 .1016/j.jand.2016.08.006

Turner, H. M., Rose, K. S., \& Cooper, M. J. (2005). Schema and parental bonding in overweight and nonoverweight female adolescents. International Journal of Obesity, 29, 381-387. http://dx.doi.org/10.1038/sj.ijo .0802915

*van Zutphen, M., Bell, A. C., Kremer, P. J., \& Swinburn, B. A. (2007). Association between the family environment and television viewing in Australian children. Journal of Paediatrics and Child Health, 43, 458463. http://dx.doi.org/10.1111/j.1440-1754.2007.01111.x

*Vereecken, C. A., Keukelier, E., \& Maes, L. (2004). Influence of mother's educational level on food parenting practices and food habits of young children. Appetite, 43, 93-103. http://dx.doi.org/10.1016/j.appet.2004.04 .002

Viechtbauer, W. (2010). metafor: Meta-analysis package for R (Version R package version 1.4-0) [Computer software]. Retrieved from http:// CRAN.R-project.org/package $=$ metafor

*Wenhold, H., \& Harrison, K. (2018). Television use and family mealtimes among a sample of U.S. families with preschoolers. Journal of Children and Media, 12, 98-115. http://dx.doi.org/10.1080/17482798.2017.1395751

Wildermuth, S. A., Mesman, G. R., \& Ward, W. L. (2013). Maladaptive eating patterns in children. Journal of Pediatric Health Care, 27, 109119. http://dx.doi.org/10.1016/j.pedhc.2011.07.009

Received December 13, 2018 Revision received June 25, 2019 Accepted July 21, 2019 